\section{Call for papers} Abstracts seleccionados

\section{Cuando la actitud deviene en forma* Marta Pelegrín Rodríguez}

D esde principios de los noventa es posible identificar en alpropuesta constructiva singular. Sus obras muestran una "actitud" pragmática y casi experimental de la arquitectura, que vincula intensamente la teoría y la práctica material. Se caracterizan por proponer nuevos programas o hibridaciones de los mismos, y atienden a los procesos de proyecto y construcción que relacionan al individuo con su entorno ambiental y social sin una "forma" predefinida, abierta, con una materialidad sencilla, ligera e "intensa".

Este artículo propone el estudio y reflexión de algunas arquitectura realizadas en el cambio de siglo, que tienen importantes referentes a lo largo del siglo XX en diversos campos artísticos y que, gracias a la implicación en numerosas ocasiones con arquitectos, es incorporada en la reflexión, creación y construcción arquitectónica de forma singular en el XXI. Lejos de entender la arquitectura como disciplina fundamentada en el significado y el discurso, se propone la experimentación como fuente de conocimiento, lo cotidiano como práctica material esencial, la técnica como un medio operativo y eficaz, la ecología como material de trabajo.

Son proyectos que condensan y manifiestan en la obra construida una forma singular y radical (en cuanto a sus raíces) de proponer aspectos esenciales para la arquitectura, que devienen en una intensilicación de la relación con el medio urbano, social, técnico y productivo en que se construyen. Se trata de una transición de la arquitectura discursiva a la práctica material que, tal
vez aún poco teorizada, se documenta e ilustra en este artículo. Traducción del título de la exposición organizada por Harald Szeemann en la
Kunsthalle de Berna, 1969, When Attitudes Become Form: works, concepts,
process, situations, information.
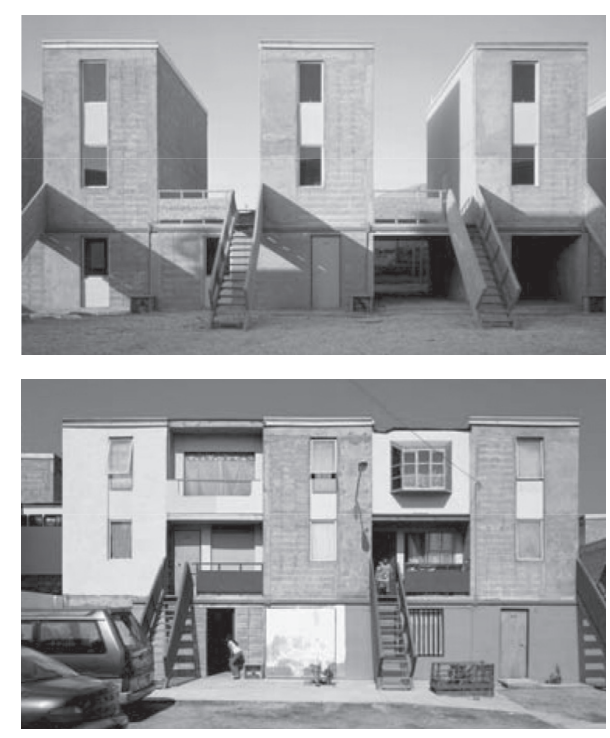

Elemental, Quinta Monroy. Chile, 2007

\section{La autoconstrucción como sistema}

Roger Sauquet Llonch

os mecanismos proyectuales ideados para desarrollar moL delos habitacionales abiertos a la acción constructiva del usuario pueden constituir, en sí mismos, sistemas. Más allá de abordar la necesidad o conveniencia de dejar la consolidación arquitectónica de la vivienda en manos del usuario, o de la idoneidad de que la vivienda, como si de un organismo se tratara pueda crecer a lo largo de los años, el artículo revisa y analiza estos mecanismos considerándolos herramientas útiles para la para la estructuración del hábitat humano.

Aunque John Burroughs idealizara a finales del siglo XIX, en su ensayo Construirse la casa , el Do It Yourself ${ }^{1}$ habitacional como parte indispensable del crecimiento humano, es la modernidad arquitectónica la que ofrece los mecanismos geométricos necesarios para ordenar el peligroso caos (peligroso en tanto que insolidario) de la autoconstrucción. En la ciudad contemporánea la autoconstrucción toma un significado muy distinto al que tenía en un paisaje de praderas infinitas y casas aisladas. ¿Son, sin embargo, el orden urbano, la convivencia, la igualdad, motivos de peso para aniquilar la pretensión de los habitantes a "moldearse" su casa? Algunos arquitectos parecen haber encontrado respuestas para decir que no, que no siempre está reñida la ciudad contemporánea con la ilusión de la autoconstrucción.

El artículo revisa estas respuestas presentes hoy, por ejemplo, en proyectos de nuevos barrios de Latinoamérica, recorriendo desde Le Corbusier hasta Siza Vieira distintos pasajes arquitectónicos como el metabolismo, el anarquismo arquitectónico de Freedom o los primeros proyectos vacacionales.

1 BORROUGHS, John. Construirse la casa, seguido de Miradas a la naturaleza.
Jose de J. Olañeta Ed. 2011 .

\title{
Arquitectura y estructuras Un ejemplo clásico: la Ville Savoie
}

\section{Moisés Gallego}

L presente reflexión versa sobre la relación intima que - hay entre la arquitectura y aquello que la sustenta, o es equivalente a lo que es el esqueleto en la especie humana. En este ejemplo la osamenta tiene una relacion directa con la forma física de la persona. Los diferentes huesos, nudos y articulaciones están directamente relacionados con el movimiento y su estabilidad. La relación entre el ser humano movimiento y su estabilidad. La relación entre el ser humano dan solidez a la musculatura y vehiculan la transmisión de carg solidez a la musculatura y vehiculan la transmisión de cargas. La función de transporte de estas cargas por parte de la osamenta es tan directa que, analizando la estructupuede afirmar que los gigantes no pueden existir más allá de la mitología.

En el territorio de la arquitectura la estructura opera del mismo modo sobre el edificio. El transporte de cargas tanto del peso de los materiales como de las sobrecargas de uso adquiere en todo edificio una relevancia considerable y por tanto es parte intrínseca de su esencia. Es obvio, por ejemplo, que el descenso de cargas a través de los elementos portantes debe llevarse hasta el suelo o mejor dicho, hasta los cimientos, ya que es en este plano donde se produce el equilibrio de fuerzas.

Hasta mediados del siglo XIX esta transmisión de cargas se hizo a través de muros y paredes maestras. El desligar estos elementos de su habitual peaje dejando que esta función quedara a cargo de un sistema estructural independiente fue uno de los factores de cambio más importantes que se produjeron a inicios del siglo pasado. A partir de entonces, y sobre todo de las reflexiones de Le Corbusier sobre el tema, tanto las paredes exteriores como las interiores de carga se libraron de esta servitud. Con ello se iniciaron nuevos valores para la arquitectura

Este cambio fue hábilmente asumido por el movimiento moderno. El resultado no se hizo esperar. Los edificios empezaron a adquirir unas formas hasta entonces desconocidas. Como consecuencia de esta liberación los planos de fachadas podían incorporar grandes ventanales, ventanas corridas, entrepaños de espesores muy delgados, composiciones inusuales, etc.

Las fachadas, liberadas de todo ornamento manifestaron una libertad compositiva desconocida hasta el momento. Fue un nuevo proceso que abarco proyecto y obra, que a fecha de hoy no ha concluido. Conviene afirmar que lo que sí se ha consolidado es un nuevo concepto en esta estrecha relación entre estructura y edificio.

En los primeros compases de este cambio y en torno a los años 30, la Ville Savoye, de Le Corbusier, ejemplariza a la perfección estos nuevos valores. En ella los conceptos de una nueva arquitectura se muestran con maestría y belleza. La residencia se levanta del suelo, mediante un sistema modulado de pilares que genera una estructura ritmada en el exterior.

La ortogonalidad de la red estructural que soporta el edificio se manifiesta exteriormente a través de un porche corrido en odo su perímetro. La planta noble se relaciona con el exterior elevando el punto de vista de sus moradores, como ya ocurriera en los antiguos palacetes ochocentistas. En la Ville Savoye todo es nuevo y todo parece conocido. A día de hoy, y ya con casi un siglo de vida, este edificio sigue mostrando vigencia en estos valores de modernidad (fig.1).

Vayamos a lo nuestro que no es otra cosa que el binomio con el que hemos escogido la relación entre arquitectura y estructura. La planta no es un cuadrado perfecto, ya que tiene un par de metros más de fondo que de ancho, lo que equivale a decir que los vanos son de diferentes medidas. La estructura periférica es por ambos lados de 4 parteluces y 5 pilares lo que daría a la retícula un total de 25 pilares, pero en la planta baja esto no es exactamente así; razones funcionales hacen que la retícula que ordena la disposición de pilares se interrumpa en algunas partes interiores. En total aparecen 32 pilares, que notablemente rompen la regla general.

Centrándonos en los pórticos del perímetro se constata que hay 5 pilares por lado, lo que quiere decir que en ninguna de las fachadas el eje de simetría coincide con el centro del vano, sino con el eje de un pilar. Quedémonos con que esta razón de orden y composición fue siempre desechada en la arquitectura tradicional. Aún hay más: en las fachadas laterales los pilares no arrannal. Aun hay mas: en las fachadas laterales los pilares no arrancan en el diedro de las esquinas, sino que aparecen voladizos y el porche periférico lo es solamente por tres lados. Las zonas de la fachada de acceso respecto de las tres restantes.

En el centro de la segunda crujía estructural, o sea, pasada la puerta de entrada, aparecen un par de pilares, uno a cada lado de la rampa de la promenade architecturale. Pilares que en la planta superior (planta noble) han sido sustituidos por uno centrado en el vano. Dicho al revés y mirando de abajo hacia arriba: en la segunda crujía hay un pilar que no tiene continuidad vertical en planta baja. Esta operación de hacer desaparecer un pilar por otros dos simétricamente separados se denomina, en el lenguaje común de la construcción, un brochal.

Esta pequeña contrariedad no le quita ni un ápice de valor al proyecto y obra. La Ville Savoye es una residencia de planta baja y piso y en esta ocasión la transmisión de cargas sobre el brochal es de poca cuantia. En estas condiciones el nudo se resuelve sin mayores problemas

En términos muy generales los brochales suelen indicar un desacuerdo entre orden de estructura y de espacio. Este desajuste supone introducir, en el plano del de transmisión de cargas, un conjunto de esfuerzos complementarios de torsión y flexión que conviene evitar siempre que sea posible. Cuando esto ocurre suele pensarse que es un desajuste y, utilizando un tono irónico, un pequeño fallo; independientemente de que se ha dado en innumerables obras sin mayor trascendencia. Dibujando las tensiones, deformaciones y reparto de cargas en el caso de un brochal con estructura ortogonal y el de una estructura triangulada se comprueba como el esquema triangulado reduce tensiones y esfuerzos a flexión siendo un contrapunto al anterior.

Esta pequeña contrariedad no le quita ni un ápice de valor a proyecto y obra. La Ville Savoye es una residencia de planta baja y piso y en esta ocasion la transmisión de cargas sobre e brochal es de poca cuantia. En estas condiciones el nudo se resuelve sin mayores problemas. El edificio ofreció tal cantidad en este desajuste no pretende ir más allá de una simple observación al tema propuesto. Baste decir que, en otras obras posteriores del mismo autor, el rigor estructural adquiere valores modélicos, como por ejemplo en el centro de artes visuales del edificio Carpenter de la universidad de Harvard.

Se trata de un equipamiento universitario donde la estructura de hormigón armado es el elemento que define la obra. Esta se caracteriza por dos cuerpos curvos atravesados por una rampa en diagodel perímetro se amoldan al orden estructural de manera ejemplar.

Moisés Gallego es Doctor arquitecto y profesor del Departamento de Proyectos Arquitectónicos de la E.T.S.A.Barcelona

Fig. 1 Le Corbusier. Ville Savoie. Plantas baja, piso y sección
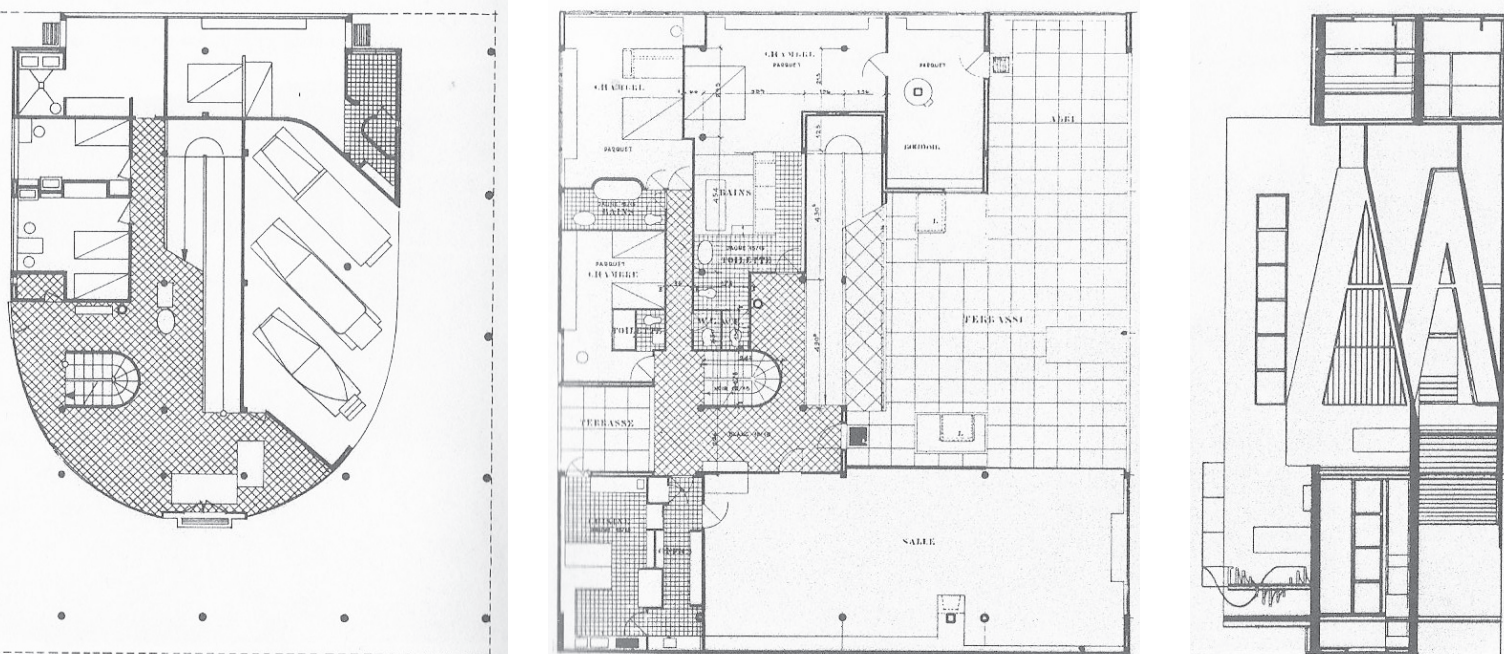